www.jmscr.igmpublication.org

Impact Factor 5.84

Index Copernicus Value: 71.58

ISSN (e)-2347-176x ISSN (p) 2455-0450

crossref DOI: _https://dx.doi.org/10.18535/jmscr/v5i10.185

Journal Of Medical Science And Clinical Research

IGM Publication

An Official Publication of IGM Publication

\title{
Hesperidin and Experimentally-Induced Arthritis in Male Rats
}

\author{
Authors \\ Hader I. Sakr ${ }^{1}$, Akef A. Khowailed ${ }^{1}$, Nermeen A. Bastawy ${ }^{1}$, Safy S. Gaber ${ }^{2}$, \\ Osama M. Ahmed ${ }^{3}$, and Asmaa S. Gaber ${ }^{4}$ \\ ${ }^{1}$ Department of Medical Physiology, Kasr Al-Aini Faculty of Medicine, Cairo University, Egypt \\ ${ }^{2}$ Department of Medical Physiology, Faculty of Medicine, Beni-suef University, Egypt \\ ${ }^{3}$ Department of Physiology, Faculty of Science, Beni-suef University, Egypt \\ ${ }^{4}$ Department of Clinical Pathology, Faculty of Medicine, Beni-suef University, Egypt \\ Corresponding Author \\ Hader Ibrahim Sakr, M.D., Ph. D. \\ Medical Physiology Lecturer, Kasr Al-Ainy Faculty of Medicine, Department of Physiology \\ Cairo University, Egypt \\ T: (002) 011-11616364/F: (002) 272-72148 / Email: hadersakr@kasralainy.edu.eg
}

\begin{abstract}
Background: Rheumatoid arthritis (RA), the most common cause of arthritis, is a chronic autoimmune disease of multifactorial etiology characterized by synovial hyperplasia, autoantibody production, cartilage and bone destruction, joint malformation and systemic features in the form of cardiovascular, pulmonary, psychological, and skeletal disorders. Its prevalence is $1 \%$ of the population. The pathogenesis of RA is still not fully understood. RA starts by a cascade of inflammatory events lead to degradation of tissues. It is characterized by low interferon $\gamma$ (IFN

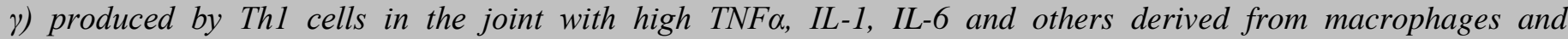
synoviocytes. High levels of serum TNFa, IL-1cause synovial inflammation and joint damage, activates tissuedestroying matrix metalloproteinases, and additionally stimulates the development of osteoclasts, which are responsible for bone degradation. Treatment strategies for RA include steroids, NSAID's, immunosuppressant agents, DMARD, among others; however, they have their own share of side effects and toxicities. Thus, naturally originated drugs are highly desired to substitute chemical therapeutics. The present study was designed to evaluate the possible effect of hesperidin on RA in male rats and to explain the possible mechanisms underlying such effect.

Animals and Methods: 36 male albino rats were divided into two main groups kept under observation for one week (group I) and two weeks (group II). Each group was divided into three subgroups: normal (subgroup A), RA (subgroup B) and oral hesperidin $(25 \mathrm{mg} / \mathrm{kg}$ ) treated (subgroup C). Ankle diameter, serum $R F, I L-1 \beta, T N F \alpha, I L-4, I L$ 10, livers homogenates MDA, GSH, SOD and NO were measured in addition to right ankle joints histopathological examination.

Results: Hesperidin treatment to the rheumatic rats was associated with decreased ankle diameter, serum RF, IL-1 $\beta$, $T N F \alpha$ and liver homogenates MDA and NO, and increased serum IL-4 and IL-10 and liver homogenates GSH and SOD with reduced inflammatory cell infiltrate and necrosis of articular cartilage compared to arthritic group. Two weeks treatment showed better results than one week treatment.

Conclusion: Hesperidin have pronounced useful effects in alleviating the disturbed ankle diameter, serum $R F, I L-1 \beta$, $T N F \alpha, I L-4, I L-10$, oxidative stress in liver homogenate and ankle joint histopathology in rheumatic male rats.

Keywords: Rheumatoid arthritis, ankle edema, hesperidin, oxidative stress.
\end{abstract}




\section{Introduction}

Rheumatoid arthritis (RA) is a chronic systemic autoimmune disease that characterized by persistent synovial inflammation and progressive destruction of both joint cartilage and bone tissues (1). Worldwide prevalence of RA has been estimated to be $0.5-1.0 \%$ of adults in developed countries and it is approximately three-times more common in the female gender. RA may begin at any age, but in around $80 \%$ of all patients it initiates between the ages of 35 and 50 years ${ }^{(2)}$. Altered immune response explains the pathophysiology of RA. Pro-inflammatory cytokines as TNF- $\alpha$ and IL- $1 \beta$ are considered the main contributors in the pathogenesis of RA. Joint destruction and systemic bone loss is cause by prolonged immune activation ${ }^{(3)}$. It is noted that many RA patients suffer from severe adverse side effects such as gastrointestinal ulcergenicity, cardiovascular complication, hematologic toxicity and renal morbidity ${ }^{(4)}$.

Patients with RA are treated mainly by synthetic medicines belonging to NSAIDs combined with the steroid hormones or disease-modifying antirheumatic drugs (DMARDs). Although, these drugs suppress inflammation and ameliorate symptoms, but they do not significantly improve the long-term disease outcome ${ }^{(5)}$. Several studies considered herbal medicines as a potentially important avenue leading to novel therapeutic agents for RA that may not only prevent structural damage of arthritic joints caused by tissue and bone breakdown, but also be safe, relatively inexpensive, highly tolerated and convenient for many patients $^{(6)}$. Hesperidin is a naturally occurring flavonoid. Its highest concentrations are found in citrus fruit peels. Also, it occurs in all parts of plants including fruit, vegetables, nuts, seeds, leaves, flowers and bark. Hesperidin is an effective antioxidant and anti-inflammatory agent. It has anti-arthritic and anti-atherogenic effect ${ }^{(7)}$.

The present study was designed to investigate the possible effect of the use of hesperidin on progression of adjuvant-induced arthritis in male rats.

\section{Materials\& Methods}

\section{I-Experimental Animals}

Thirty six adult male albino rats weighing 100$120 \mathrm{~g}$ were used as experimental animals in the present study obtained from the animal house of Kasr Al Aini, Faculty of Medicine, Cairo University. They were kept under observation for about 15 days before the onset of the experiment for adaptation and to exclude any intercurrent infection. The chosen animals were housed (four per cage) in plastic cages with good aerated covers in the animal house of Zoology Department, Faculty of Science, Beni-Suef University, at normal temperature $\left(25 \pm 5^{\circ} \mathrm{C}\right)$ with 12 hours light/dark cycles. They were given access of water and supplied daily with standard diet of known composition. All experimental protocols described in the present study were approved by the Ethics Review Committee for Animal Experimentation of the National Institutes of Health Guidelines for the Care and Use of Laboratory Animals of Faculty of Science, Beni-Suef University with approval number: BSU/FM/2015/1.

\section{II-Drug Preparation}

Complete Freund's adjuvant (CFA) and hesperidin were purchased from Sigma Chemicals Co., St. Louis, MO, USA, stored at $2-4{ }^{\circ} \mathrm{C}$ and protected from sunlight. Hesperidin was dissolved in $5 \mathrm{ml}$ of $1 \%$ carboxymethylcellulose (CMC) solution as a vehicle and was given by oral gavage daily for the period of the study.

\section{III - Induction of Rheumatoid Arthritis}

Adjuvant arthritis was induced by a single subcutaneous injection of $0.1 \mathrm{ml}$ complete Freund's adjuvant (CFA), a suspension of heatkilled Mycobacterium tuberculosis in mineral oil into a footpad of the right hind leg of male rats. The inflammatory manifestations as redness, edema, and hyper-responsiveness to noxious stimuli were limited to the injected paw. Inflammation started to appear shortly after the injection and was peaked after 14 days ${ }^{(8)}$. 


\section{IV-Animals Grouping}

The considered rats were divided into two main groups kept under the same laboratory conditions as follows:

Group I: Kept for one week.

Group II: Kept for two weeks.

Each group was divided into three subgroups with six animals each as follows:

Subgroup A (control subgroup): Animals were given oral equivalent volume of CMC.

Subgroup B (RA subgroup): RA was induced on day 0 of the experiment. Rats were given oral equivalent volume of CMC.

Subgroup C (RA treated with hesperidin subgroup): RA was induced on day 0 of the experiment. Rats were administrated oral 25 $\mathrm{mg} / \mathrm{kg}$ of hesperidin ${ }^{(9)}$.

All treatments were given orally daily between 8:00 and 10:00 am.

\section{VI- Animals scarification and samples collection}

At the end of 1 st and 2nd week, rats of each subgroup were sacrificed under diethyl ether anesthesia. The ankle circumference of right hind leg was measured and blood was collected from jugular vein. Serum was separated by centrifugation of blood at $3000 \mathrm{rpm}$ for 15 minutes and the clear non-hemolysed supernatant sera were quickly removed, divided into three portions for each individual animal and kept at $20^{\circ} \mathrm{C}$ till used. Ankle regions were removed, fixed in $10 \%$ neutral buffered formalin for histopathological examination.

Liver from each animal was excised after dissection, cleaned of blood, later blotted with a clean tissue paper, weighed and $0.5 \mathrm{~g}$ from each liver was homogenized in $5 \mathrm{ml} 0.9 \% \mathrm{NaCl}(10 \%$ w/v) using Teflon homogenizer (Glas-col, Terre Haute, USA). The supernatant homogenate for each liver sample was obtained by centrifuging the homogenate at 3000 r.p.m. for 5 minutes. The obtained supernatant of each sample was kept at $20^{\circ} \mathrm{C}$ until used for detection of parameters of oxidative stress (malondialdehyde "MDA" and nitric oxide "NO") and antioxidant defense system (reduced glutathione "GSH" and super oxide dismutase "SOD").

\section{VII- Experimental Studies}

\section{VII- 1- Detection of ankle diameter:}

At the end of the experimental period, the right hind leg circumference at region of paw was measured as an indicator of swelling rate and paw edema in different groups using a string wrapped around the leg at region of paw. The length of the string was measured by a ruler. Measurements were taken on the $7^{\text {th }}$ and $14^{\text {th }}$ days after adjuvant injection.

\section{VII- 2 Determination of serum RF concentration}

The level of RF in the serum of the groups were determined using specific enzyme-linked immunosorbent assay (ELISA) kits purchased from $\mathrm{R}$ and A systems, USA according to manufacturer's instructions.

\section{Principle}

RF ELISA kit applies the competitive enzyme immunoassay technique utilizing a monoclonal anti-RF antibody and an RF-HRP conjugate. The assay sample and buffer were incubated together with RF-HRP conjugate in pre-coated plate for one hour. After the incubation period, the wells were decanted and washed five times. The wells were then incubated with a substrate for HRP enzyme. The product of the enzyme-substrate reaction formed a blue colored complex. Finally, a stop solution is added to stop the reaction, which then turns the solution yellow. The intensity of color was measured spectrophotometrically at 450 $\mathrm{nm}$ in a microplate reader. The intensity of the color was inversely proportional to the RF concentration since RF from samples and RFHRP conjugated compete for the anti-RF antibody binding site. Since the number of sites was limited, as more sites were occupied by RF from the sample, fewer sites were left to bind RF-HRP conjugate. A standard curve was plotted relating the intensity of the color (O.D.) to the concentration of standards. The RF concentration in each sample was interpolated from this standard curve. 
VII- 3- Determination of serum TNF- $\alpha$, IL-1 $\beta$, IL-4 and IL-10 concentrations

The level of TNF- $\alpha$ in the serum of the groups were determined using specific ELISA kits purchased from $\mathrm{R}$ and A systems, USA according to manufacturer's instructions ${ }^{(10)}$. Serum IL-1 $\beta$ was determined by ELISA kits obtained from Thermo Scientific (USA) according to manufacturer's instructions. The level of IL-4 in the serum of the groups was determined using specific ELISA kits purchased from $\mathrm{R}$ and $\mathrm{A}$ systems, Inc., USA according to manufacturer's instructions. The level of IL-10 in the serum of the groups was determined using specific ELISA kits purchased from $\mathrm{R}$ and $\mathrm{A}$ systems, USA. The concentrations of IL-10 were determined using spectrophotometer at $450 \mathrm{~nm}$ according to the manufacturer's instructions ${ }^{(11)}$.

\section{Principle}

This assay employs the quantitative sandwich enzyme immunoassay technique. Monoclonal antibodies specific for rat TNF- $\alpha$, IL-1 $\beta$, IL-4 or IL-10 were pre-coated onto a microplate. Standards control, and samples were pipetted into the wells and any rat TNF- $\alpha$, IL-1 $\beta$, IL-4 or IL-10 present were bound by the immobilized antibody. After washing away any unbound substances, Enzyme-linked polyclonal antibodies specific for rat TNF- $\alpha$, IL-1 $\beta$, IL-4 or IL-10 were added to the wells. Following a wash to remove any unbound antibody-enzyme reagent, a substrate solution was added to the wells. The enzyme reaction yields a blue product that turns yellow when the Stop Solution is added. The intensity of the color measured was in proportion to the amount of rat TNF- $\alpha$, IL-1 $\beta$, IL- 4 or IL-10 bound. Sample values were then read off of the standard curve.

VII- 4 - Determination of nitric oxide concentration in Liver homogenate

Liver homogenates were used to determine nitric oxide (NO) using Nitric Oxide (NO2-/NO3-) assay Kit (Assay Designs, Ann Arbor, MI, USA) according to manufacturer's instructions ${ }^{(12)}$.

\section{Principle}

Greiss reagent was used for the quantitative colorimetric determination of $\mathrm{NO}$ levels as total nitrate/nitrite. To reduce nitrate to nitrite, vanadium trichloride and then Griess reagent was added and incubated at $37^{\circ} \mathrm{C}$. The absorbance was measured after allowing the mixture to cool at 540 $\mathrm{nm}$. Results were expressed as $\mu \mathrm{mol} / \mathrm{g}$ tissue.

\section{VII- 5 - Determination of liver homogenate lipid peroxidation concentration}

Liver homogenate lipid peroxidation was determined according the method of Ohkawa et al. (13)

\section{Principle}

Thiobarbituric acid (TBA) reacts with MDA in acidic medium at temperature of $95^{\circ} \mathrm{C}$ for $30 \mathrm{~min}$. to form TBA reactive product. The absorbance of the resultant pink product can be measured at 534 $\mathrm{nm}$.

VII- 6 - Determination of the liver homogenate reduced glutathione concentration

Reduced glutathione concentration in the liver homogenate of the groups was determined according to Tietze's method ${ }^{(14)}$.

\section{Principle}

The assay is based on the reaction of GSH with Ellman's reagent (also known as 5, 5'-dithio bis2nitrobenzoic acid (DTNB)) that produces the TNB chromophore, which has a maximal absorbance at $412 \mathrm{~nm}$, and oxidized glutathione- TNB adduct (GS-TNB). The rate of formation of TNB, measured at $412 \mathrm{~nm}$, is proportional to the concentration of GSH in the sample. The disulfide product (GS-TNB) is then reduced by GR in the presence of NADPH, recycling GSH back into the reaction. Because GR reduces the GSSG formed into $2 \mathrm{GSH}$, the amount of glutathione measured represents the sum of reduced and oxidized glutathione in the sample $([\mathrm{GSH}]$ total $=[\mathrm{GSH}]+$ $2 \times[$ GSSG] $)$. The rate of change in absorbance $(\triangle \mathrm{A} 412 \mathrm{~nm}$ min-1) is made to be linear for the convenience and consistency of measurement, and is linearly proportional to the total concentration of GSH. The concentration of an unknown sample is determined by calculating from the linear 
equation or the regression curve generated from several standards of GSH.

VII- 7 - Determination of the liver homogenate superoxide dismutase concentration

SOD activity in liver homogenate was assayed according to the method of Marklund and Marklund ${ }^{(15)}$.

\section{Principle}

The pyrogallol is auto-oxidized rapidly in aqueous solution to produce a yellow color that can be read at $430 \mathrm{~nm}$. This process is dependent on the presence of superoxide anions. SOD inhibits the auto-oxidation of the pyrogallol by catalyzing the breakdown of superoxide. The amount of enzyme that cause a $50 \%$ resistance in the extinction changes in 1 minute compared to the control can be regarded as one unit of enzyme. To $0.5 \mathrm{ml}$ of tris buffer, $0.25 \mathrm{ml}$ of the homogenate supernatant was added. The initial absorbance was read after the addition of $0.1 \mathrm{ml}$ pyrogallol and at 10 minutes after the addition. Distilled water $(0.25$ $\mathrm{ml}$ ) instead of homogenate supernatant was used in control preparation. $\Delta \mathrm{E}$ is obtained by subtraction of the final absorbance from the initial one. Each $50 \%$ inhibition is equivalent to 1 unit of the enzyme activity.

\section{VII- 8 - Histopathological investigation}

After sacrifice and dissection, ankle regions were removed, washed in saline and fixed in 10\% neutral buffered formalin. The ankle regions were decalcified for 10 days with ethylene-diaminetetra-acetic acid and embedded in paraffin for histological analysis in Histopathology Department, Faculty of Veterinary Medicine, Beni-Suef University. The sections were stained with hematoxylin and eosin, and then examined by light electric microscope.

\section{VIII- Statistical Analysis}

Data were coded and entered using the statistical package SPSS version 23. Data were summarized using mean and standard deviation for quantitative variables. Comparisons between groups were done using unpaired t test when comparing 2 groups and analysis of variance (ANOVA) with multiple comparisons post hoc test when comparing more than 2 groups ${ }^{(16)}$. P-values less than 0.05 were considered statistically significant.

$\%$ change after rheumatoid arthritis induction and drug administration was calculated using the equation:

$\%$ Change $=\frac{\mathrm{V} 1-\mathrm{V} 2}{\mathrm{~V} 2}$

Where:

$\mathrm{V} 1=$ New value of treated groups.

$\mathrm{V} 2=$ Control value obtained from rheumatic rats.

Values are presented as mean \pm SD. Results considered statistically significant if $(\mathrm{P}<0.05)$.

\section{Results}

The present work studied the effect of the use of hesperidin on ankle diameter, serum RF,IL-1 $\beta$, TNF $\alpha$, IL-4, IL-10, oxidative stress and antioxidant markers in liver homogenate and ankle joint histopathology in normal and rheumatic arthritic male rats for one and two weeks.

\section{Effect on ankle diameter}

(Table 1 and figure $\mathbf{1}$ ).

After induction of RA, on day 1, there were significant swelling and inflammation in the ankle joint of right leg of rats at the site of CFA injection. This edema persists till the end of the work. After one and two weeks of induction of RA in rats, the results showed significant increase in ankle diameter (in $\mathrm{cm}$ ) in subgroup IB by $+32 \%$ and subgroup IIB by $+46.7 \%$ when compared with subgroups IA and IIA respectively. However, when observing ankle diameter after treatment of RA in rats with hesperidin for one week (subgroup IC) and two weeks (subgroup IIC), the results showed significant decrease in ankle diameter in subgroup IC by $-9.76 \%$ and in subgroup IIC by $27.33 \%$ when compared with subgroups IB and IIB respectively.

\section{One week vs. two weeks:}

When comparing the ankle diameters in subgroups IA and IIA, the results showed no significant difference between them. In case of induction of RA, the results showed significant increase in ankle diameter in subgroup IIB when compared 
with subgroup IB indicating the progression of RA. In case of hesperidin-treated rats, the results showed significant decrease in ankle in subgroup IIC when compared with subgroup IC.

Table (1): comparison of ankle diameter after one (I) and two (II) weeks in normal (A), RA (B) and hesperidin $(\mathrm{C})$ subgroups.

\begin{tabular}{|c|c|c|c|}
\hline \multirow{4}{*}{$\begin{array}{l}\text { Ankle } \\
\text { diameter (cm) }\end{array}$} & IA & IB & IC \\
\hline & $2.25 \pm 0.19$ & $2.97 \pm 0.12 *$ & $2.68 \pm 0.15 * \#$ \\
\hline & IIA & IIB & IIC \\
\hline & $2.27 \pm 0.16$ & $3.33 \pm 0.3^{\text {\#S }}$ & $2.42 \pm 0.12^{\text {S(ब) }}$ \\
\hline
\end{tabular}

Results are presented in mean $(\mathrm{cm}) \pm$ standard Statistically significant as compared to: control deviation. $\mathrm{P}<0.05$ is considered statistically significant. subgroup IA $(*)$, RA subgroup IB $\left(^{\#}\right)$, control subgroup IIA $\left({ }^{\$}\right)$, RA subgroup IIB $\left({ }^{\circledR}\right)$ and hesperidin subgroup IC $\left({ }^{\wedge}\right)$.

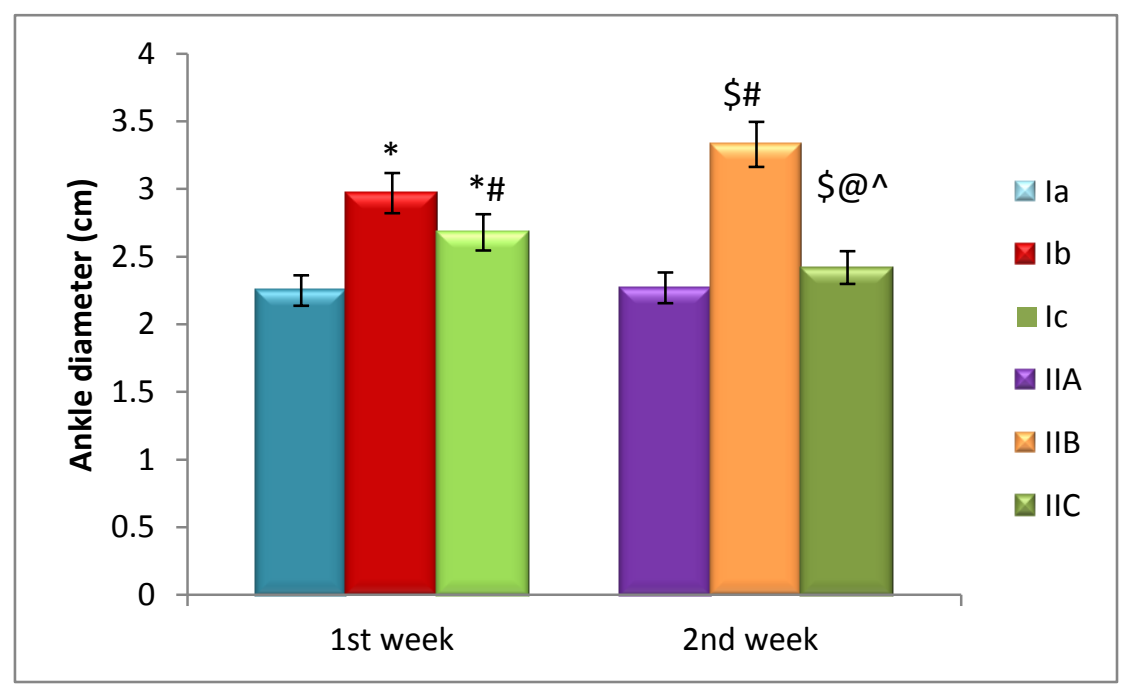

Results are presented in mean $(\mathrm{cm}) \pm$ standard deviation. $\mathrm{P}<0.05$ is considered statistically significant.

Statistically significant as compared to: control subgroup IA $(*)$, RA subgroup IB $\left(^{\#}\right)$, control subgroup IIA $\left({ }^{\$}\right)$, RA subgroup IIB $\left({ }^{@}\right)$ and hesperidin subgroup IC $\left({ }^{\wedge}\right)$.

Figure (1): comparison of ankle diameter after one (I) and two (II) weeks in normal (A), RA (B) and hesperidin (C) subgroups.

\section{Effect on serum RF level: (Table 2 and figure 2)}

After induction of RA in rats, the results show significant increase in serum RF in subgroup IB by $+132.68 \%$ and subgroup IIB by $+224.55 \%$ when compared with subgroups IA and IIA respectively. However, after treatment of RA with hesperidin for one week and for two weeks, the results showed significant decrease in serum RF in subgroup IC by $-38.91 \%$ and in subgroup IIC by $-49.52 \%$ when compared with subgroups IB and IIB respectively.

\section{One week vs. two weeks}

When comparing serum RF levels in subgroups IA and IIA, the results showed no significant difference between them. In case of induction of RA, the results showed significant increase in serum RF level in subgroup IIB when compared with subgroup IB. In case of hesperidin-treated rats, the results showed significant decrease in serum RF level in subgroup IIC when compared with subgroup IC. 
Table (2): comparison of serum RF level after one (I) and two (II) weeks in normal (A), RA (B) and hesperidin $(\mathrm{C})$ subgroups.

\begin{tabular}{|l|c|c|c|}
\hline \multirow{3}{*}{$\begin{array}{l}\text { Rheumatoid } \\
\text { factor }\end{array}$} & IA & IB & IC \\
\cline { 2 - 4 } & $10.13 \pm 2.08$ & $23.57 \pm 3.66^{*}$ & $14.40 \pm 1.44^{* \#}$ \\
\cline { 2 - 4 } & IIA & IIB & IIC \\
\cline { 2 - 4 } & $10.07 \pm 0.98$ & $34.63 \pm 3.94^{\text {\#\$ }}$ & $17.48 \pm 2.66^{\$ @ \wedge}$ \\
\hline
\end{tabular}

Results are presented in mean (IU/ml) \pm standard Statistically significant as compared to: control deviation. $\mathrm{P}<0.05$ is considered statistically significant. subgroup IA $\left(^{*}\right)$, RA subgroup IB $\left(^{*}\right)$, control subgroup IIA $\left({ }^{\$}\right)$, RA subgroup IIB $\left({ }^{@}\right)$ and hesperidin subgroup IC $\left({ }^{\wedge}\right)$.

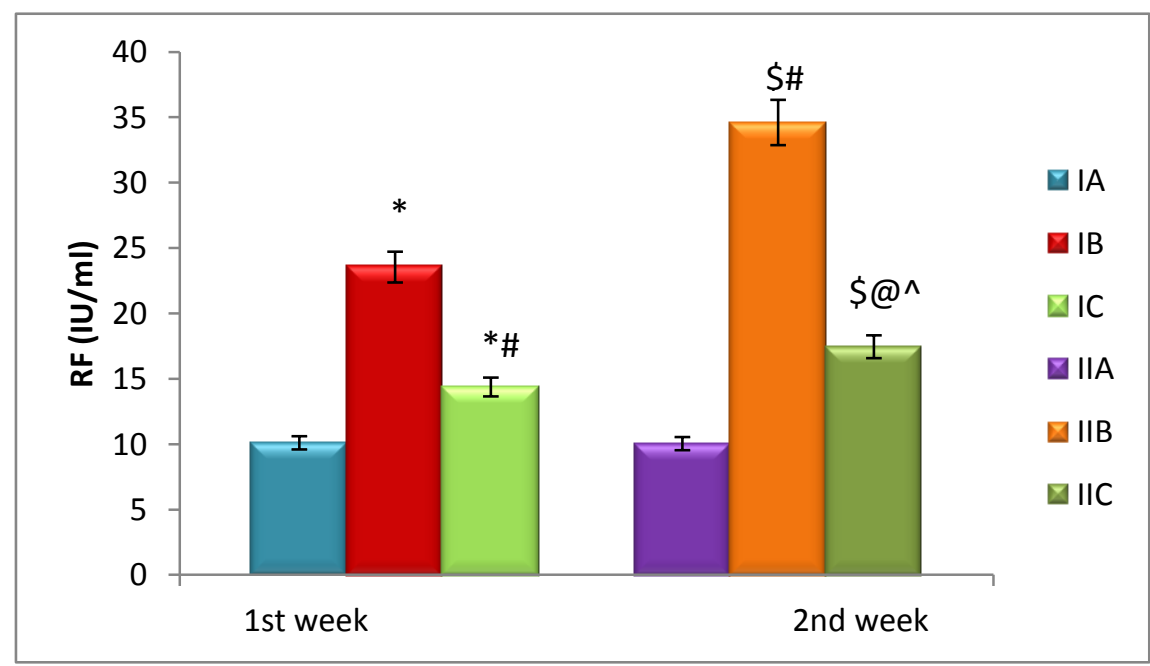

Results are presented in mean $(\mathrm{IU} / \mathrm{ml}) \pm$ standard deviation. $\mathrm{P}<0.05$ is considered statistically significant.

Statistically significant as compared to: control subgroup IA $(*)$, RA subgroup IB $\left(^{\#}\right)$, control subgroup IIA $\left({ }^{\$}\right)$, RA subgroup IIB $\left({ }^{@}\right)$ and hesperidin subgroup IC $\left(^{\wedge}\right)$.

Figure (2): comparison of serum RF level after one (I) and two (II) weeks in normal (A), RA (B) and hesperidin (C) subgroups.

\section{Effect on serum pro-inflammatory cytokines}

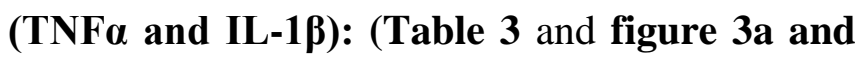
b).

After induction of RA in male rats, the administration of CFA to rats produced a significant increase in serum levels of both TNF $\alpha$ $(+170.66 \%$ and $+252.56 \%)$ and IL-1 $\beta(+310.90$ $\%$ and $+519.72 \%)$ in subgroups IB and IIB as compared to subgroups IA and IIA respectively. However, after treatment of RA with hesperidin for one week and for two weeks, the results showed significant decrease in serum TNF $\alpha$ level $(-52.61 \%$ and $-51.30 \%)$ and IL-1 $\beta$ levels ($40.40 \%$ and $-58.85 \%)$ in subgroups IC and IIC when compared with subgroups IB and IIB respectively.

\section{One week vs. two weeks}

When comparing serum TNF $\alpha$ and IL- $1 \beta$ levels in subgroups IA and IIA, the results showed no significant difference between them. In case of induction of RA, the results showed significant increase in serum TNF $\alpha$ and IL-1 $\beta$ levels in subgroup IIB when compared with subgroup IB. In case of hesperidin-treated rats, the results showed significant decrease in serum TNF $\alpha$ and IL- $1 \beta$ levels in subgroup IIC when compared with subgroup IC. 


\section{JMSCR Vol||05||Issue||10||Page 29567-29585||October}

Table (3): comparison of serum TNF $\alpha$ and IL-1 $\beta$ levels after one (I) and two (II) weeks in normal (A), RA (B) and hesperidin(C) subgroups.

\begin{tabular}{|c|c|c|c|c|c|c|}
\hline & IA & IB & IC & IIA & IIB & IIC \\
\hline TNFa & $31.73 \pm 4.17$ & $85.88 \pm 7.97 *$ & $40.70 \pm 2.85 *^{\#}$ & $36.17 \pm 5.44$ & $127.52 \pm 5^{\# \$}$ & $62.10 \pm 6.23^{\$ @ \wedge}$ \\
\hline & IA & IB & IC & IIA & IIB & IIC \\
\hline IL-1 $\beta$ & $32.75 \pm 3.53$ & $134.57 \pm 6.88 *$ & $80.20 \pm 5.27 * \#$ & $30.93 \pm 4.8$ & $191.68 \pm 20.11^{\# \$}$ & $78.88 \pm 13.13^{\$ @ \wedge}$ \\
\hline
\end{tabular}

Results are presented in mean $(\mathrm{pg} / \mathrm{ml}) \pm$ standard deviation. $\quad \mathrm{P}<0.05$ is considered statistically significant.

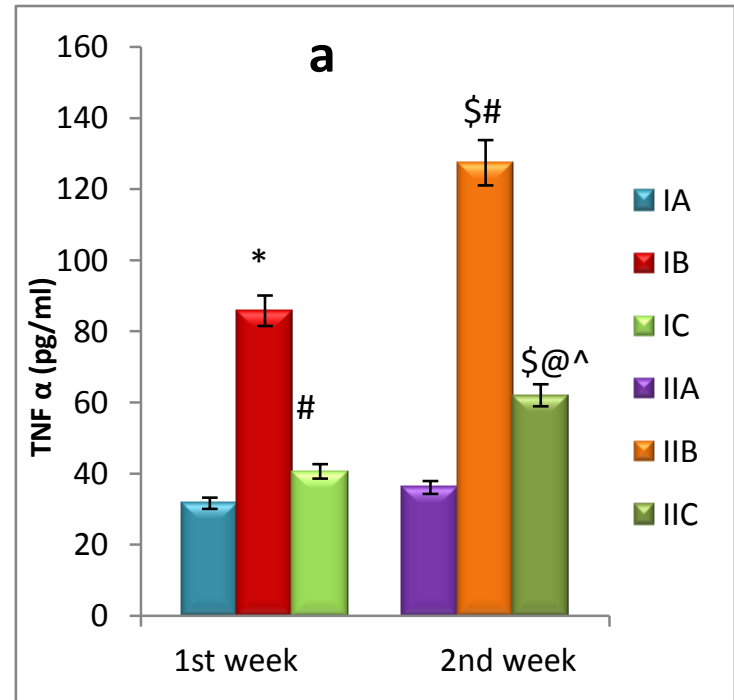

Statistically significant as compared to: control subgroup IA (*), RA subgroup IB $\left(^{*}\right)$, control subgroup IIA $\left({ }^{\$}\right)$, RA subgroup IIB $\left({ }^{\circledR}\right)$ and hesperidin subgroup IC $\left(^{\wedge}\right)$.

Results are presented in mean $(\mathrm{pg} / \mathrm{ml}) \pm$ standard deviation. $\mathrm{P}<0.05$ is considered statistically significant.

Statistically significant as compared to: control subgroup IA $\left(^{*}\right)$, RA subgroup IB $\left(^{\#}\right)$, control subgroup IIA $\left({ }^{\$}\right)$, RA subgroup IIB $\left({ }^{@}\right)$ and hesperidin subgroup IC $\left(^{\wedge}\right)$.

Figure (3): comparison of serum TNF $\alpha$ level (a) and serum IL-1 $\beta$ level (b) after one (I) and two (II) weeks in normal (A), RA (B) and hesperidin (C) subgroups.

\section{Effect on serum anti-inflammatory cytokines (IL-4 and IL-10):(Table 4 and figure $4 a$ and b).} After induction of RA in male rats, the administration of CFA to rats produced a significant decrease in serum levels of both IL-4 ($27.93 \%$ and $-41.69 \%)$ and IL-10 (-62.61 \% and $70.50 \%$ ) in subgroups IB and IIB as compared to subgroups IA and IIA respectively. However, after treatment of RA with hesperidin for one and for two weeks, the results showed significant increase in serum IL-4 level $(+28.15 \%$ and $+75.67 \%)$ and IL-10 levels (+91.60\% and +201.01\%) in subgroups IC and IIC when compared with subgroups IB and IIB respectively.

\section{One week vs. two weeks}

When comparing serum IL-4 and IL-10 levels in subgroups IA and IIA, the results showed no significant difference between them. In case of induction of RA, the results showed significant decrease in serum IL-4 and IL-10 levels in subgroup IIB when compared with subgroup IB. In case of hesperidin treated rats, the results showed significant increase in serum IL-4 and IL10 levels in subgroup IIC when compared with subgroup IC. 


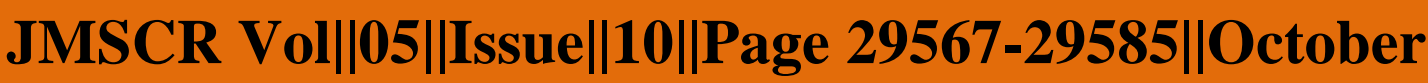

Table (4): comparison of serum IL-4 and IL-10 levels after one (I) and two (II) weeks in normal (A), RA (B) and hesperidin (C) subgroups.

\begin{tabular}{|l|c|c|c|c|c|c|}
\hline & IA & IB & IC & IIA & IIB & IIC \\
\hline IL-4 & $127.93 \pm 6.78$ & $92.18 \pm 2.31 *$ & $118.13 \pm 2.49 * \#$ & $124.65 \pm 6.02$ & $72.68 \pm 2.85 \# \$$ & $127.68 \pm 3.16 \$ @ \wedge$ \\
\hline & IA & IB & IC & IIA & IIB & IIC \\
\hline IL-10 & $129.97 \pm 3.56$ & $48.60 \pm 2.84 *$ & $93.12 \pm 2.01 * \#$ & $129.88 \pm 4.09$ & $38.32 \pm 4.69 \# \$$ & $115.35 \pm 2.44 \$ @ \wedge$ \\
\hline
\end{tabular}

Results are presented in mean $(\mathrm{pg} / \mathrm{ml}) \pm$ standard deviation. $\mathrm{P}<0.05$ is considered statistically significant.

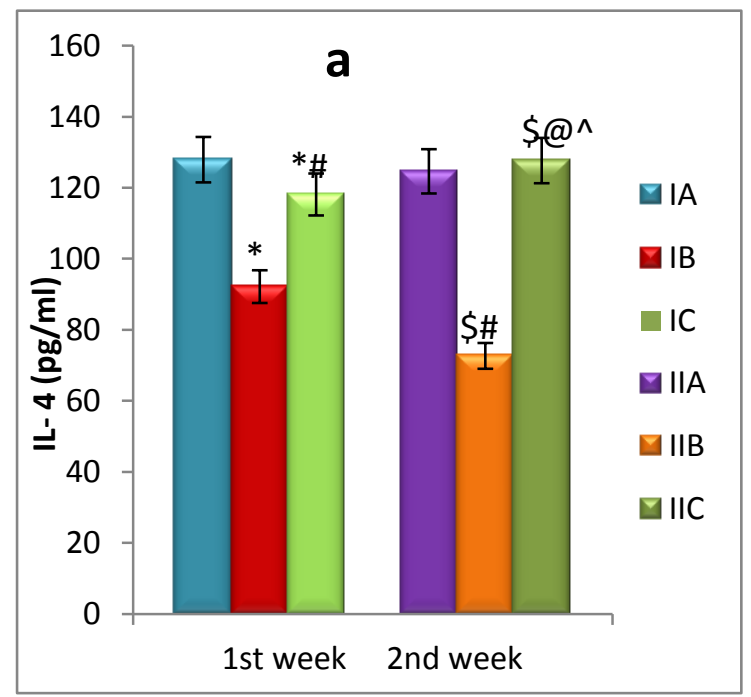

Statistically significant as compared to: control subgroup IA $\left(^{*}\right)$, RA subgroup IB $\left(^{\#}\right)$, control subgroup IIA $\left({ }^{\$}\right)$, RA subgroup IIB $\left({ }^{\circledR}\right)$ and hesperidin subgroup IC $\left({ }^{\wedge}\right)$.

Results are presented in mean $(\mathrm{pg} / \mathrm{ml}) \pm$ standard deviation. $\mathrm{P}<0.05$ is considered statistically significant.

Statistically significant as compared to: control subgroup IA $\left(^{*}\right)$, RA subgroup IB $\left(^{\#}\right)$, control subgroup IIA $\left({ }^{\$}\right)$, RA subgroup IIB $\left({ }^{@}\right)$ and hesperidin subgroup IC $\left({ }^{\wedge}\right)$.

Figure (4): comparison of serum IL-4 level (a) and serum IL-10 level (b) after one (I) and two (II) weeks in normal (A), RA (B) and hesperidin (C) subgroups

Effect on liver homogenate oxidative stress biomarkers (MDA, GSH and SOD) and NO: (Tables 5 and 6 and figures $5 a$ and $b$ and $6 a$ and b).

After induction of RA in male rats, the administration of CFA to rats produced a significant increase in liver homogenates MDA $(+58.52 \%$ and $+80.37 \%)$ and $\mathrm{NO}(+119.02 \%$ and $+160.60 \%)$ and significant decrease in liver homogenates GSH $(-50.23 \%$ and $-65.64 \%)$ and SOD (-39.68\% and $-58.04 \%)$ in subgroups IB and IIB as compared to subgroups IA and IIA respectively. However, after treatment of RA with hesperidin for one and for two weeks, the results showed significant decrease in liver homogenates MDA ( $-20.45 \%$ and $-37.53 \%)$ and NO (-16.51 $\%$ and $-52.01 \%)$ and significant increase in liver homogenates GSH $(+70.94 \%$ and $+158.05 \%)$ and SOD $(+39.73 \%$ and $+126.29 \%)$ in subgroups IC and IIC when compared with subgroups IB and IIB respectively.

\section{One week vs. two weeks}

When comparing liver homogenate oxidative stress biomarkers (MDA, GSH and SOD) and NO levels in subgroups IA and IIA, the results showed no significant difference between them. In case of induction of RA, the results showed significant 


\section{JMSCR Vol||05||Issue ||10||Page 29567-29585||October}

increase in liver homogenates MDA and NO and significant decrease in liver homogenates GSH and SOD in subgroup IIB when compared with subgroup IB. In case of hesperidin treated rats, the results showed significant increase in liver homogenates GSH and SOD and significant decrease in liver homogenates MDA and NO levels in subgroup IIC as compared with subgroup IC.

Table (5): comparison of liver homogenate MDA and GSH levels after one (I) and two (II) weeks in normal (A), RA (B) and hesperidin (C) subgroups.

\begin{tabular}{|l|c|c|c|c|c|c|}
\hline & IA & IB & IC & IIA & IIB & IIC \\
\hline MDA & $113.97 \pm 2.87$ & $180.07 \pm 2.11 *$ & $143.72 \pm 3.85 * \#$ & $113.13 \pm 3.21$ & $204.05 \pm 5.12 \# \$$ & $127.48 \pm 2.27 \$ @ \wedge$ \\
\hline & IA & IB & IC & IIA & IIB & IIC \\
\hline GSH & $479.8 \pm 18.9$ & $238.8 \pm 27.3 *$ & $408.2 \pm 1.98 * \#$ & $489.8 \pm 11.1$ & $168.3 \pm 18.5 \# \$$ & $434.3 \pm 1.37 \$ @ \wedge$ \\
\hline
\end{tabular}

Results are presented in mean (nmol/g tissue) \pm standard deviation. $\mathrm{P}<0.05$ is considered statistically significant.
Statistically significant as compared to: control subgroup IA $\left(^{*}\right)$, RA subgroup IB $\left(^{\#}\right)$, control subgroup IIA $\left({ }^{\$}\right)$, RA subgroup IIB $\left({ }^{\circledR}\right)$ and hesperidin subgroup IC $\left({ }^{\wedge}\right)$.

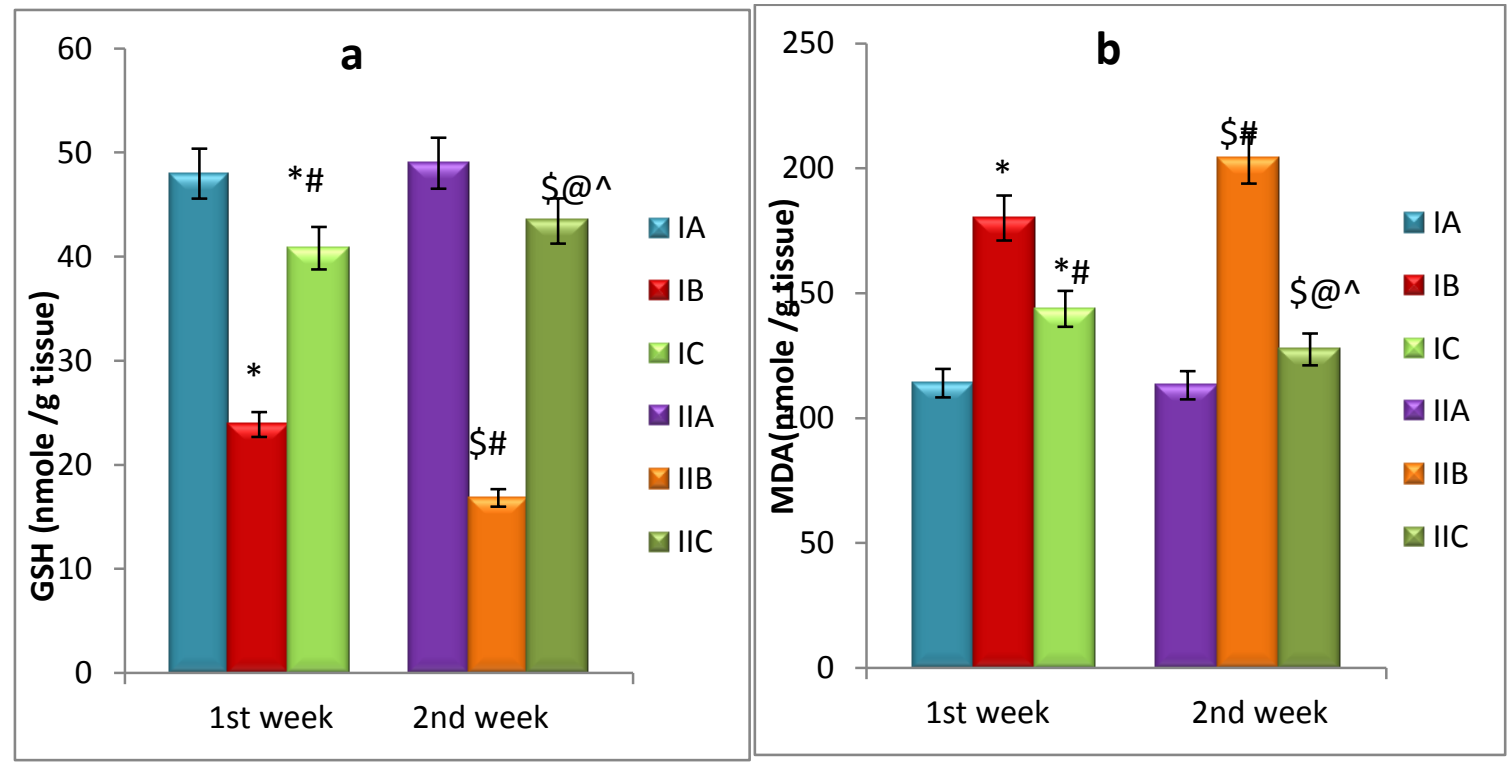

Results are presented in mean (nmol/g tissue) \pm standard deviation. $\mathrm{P}<0.05$ is considered statistically significant.

Statistically significant as compared to: control subgroup IA $\left(^{*}\right)$, RA subgroup IB $\left(^{\#}\right)$, control subgroup IIA $\left({ }^{\$}\right)$, RA subgroup IIB $\left({ }^{@}\right)$ and hesperidin subgroup IC $\left(^{\wedge}\right)$.

Figure (5): comparison of liver homogenate GSH level (a) and liver homogenate MDA level (b) after one (I) and two (II) weeks in normal (A), RA (B) and hesperidin(C) subgroups. 
Table (6): comparison of liver homogenate SOD and NO levels after one (I) and two (II) weeks in normal (A), RA (B) and hesperidin (C) subgroups.

\begin{tabular}{|l|c|c|c|c|c|c|}
\hline & IA & IB & IC & IIA & IIB & IIC \\
\hline SOD & $41.73 \pm 2.40$ & $25.17 \pm 2.94 *$ & $35.17 \pm 1.91 * \#$ & $41.42 \pm 3.74$ & $17.38 \pm 2.55 \# \$$ & $39.33 \pm 1.56 \$ @ \wedge$ \\
\hline & IA & IB & IC & IIA & IIB & IIC \\
\hline NO & $7.52 \pm 1.08$ & $16.47 \pm 1.44 *$ & $13.75 \pm 1.56 * \#$ & $8.30 \pm 1.07$ & $21.63 \pm 1.38 \# \$$ & $10.38 \pm 1.07 \$ @ \wedge$ \\
\hline
\end{tabular}

Results are presented in mean (U/g tissue) \pm Statistically significant as compared to: control standard deviation. $\mathrm{P}<0.05$ is considered subgroup IA (*), RA subgroup IB ( ${ }^{\#}$ ), control statistically significant. subgroup IIA $\left({ }^{\$}\right)$, RA subgroup IIB $\left({ }^{\circledR}\right)$ and hesperidin subgroup IC $\left({ }^{\wedge}\right)$.

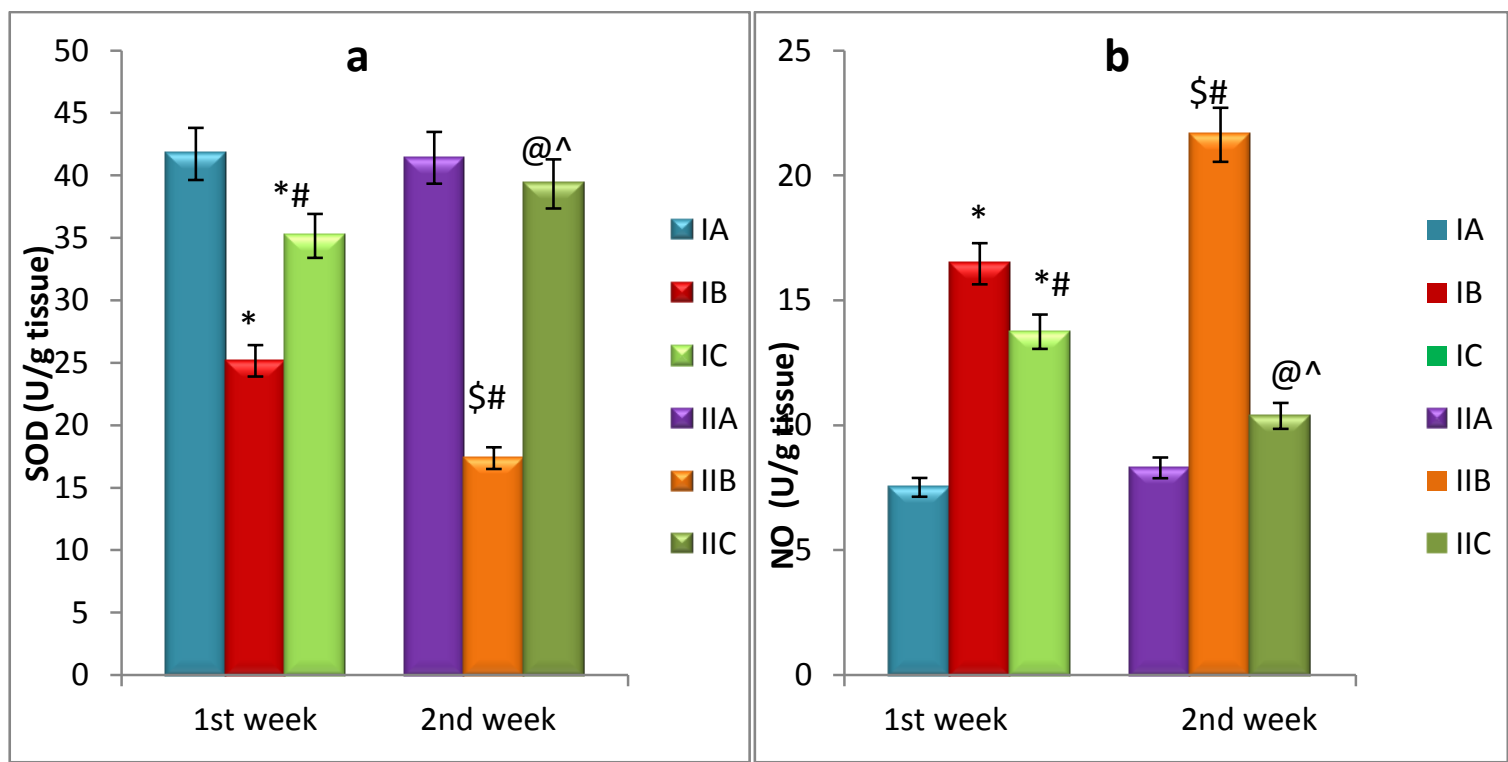

Results are presented in mean (U/g tissue) \pm standard deviation. $\mathrm{P}<0.05$ is considered statistically significant.

Statistically significant as compared to: control subgroup IA $\left(^{*}\right)$, RA subgroup IB $\left(^{\#}\right)$, control subgroup IIA $\left({ }^{\$}\right)$, RA subgroup IIB $\left({ }^{@}\right)$ and hesperidin subgroup IC $\left({ }^{\wedge}\right)$.

Figure (6): comparison of liver homogenate SOD level (a) and liver homogenate NO level (b) after one (I) and two (II) weeks in normal (A), RA (B) and hesperidin (C) subgroups.

Histopathological changes in Ankle Joints: (Figures 7a-j)

Rats in the normal subgroups IA and IIA exhibited a normal histological structure of the articular cartilage (Figures $7 \mathrm{a}, 7 \mathrm{~b}$ respectively). Conversely, both arthritic subgroups IB and IIB exhibited markedly abnormal histopathological structure, including massive synovial cell proliferation with high neovascular-ization, inflammation, infiltration with stellate cells and extensive erosive changes to articular cartilage (Figure 7c-f). Moreover, subgroup IIB showed more extensive infiltration with inflammatory cells to ankle joints (Figure 7e, 7f).On the other hand, in subgroup IC and subgroup IIC, rats exhibited only mild synovial hyperplasia, and a small number of inflammatory cells infiltration (Figure $7 \mathrm{~g}-\mathrm{j}$ ). While subgroup IIC showed new cartilage formation and less inflammatory cells (Figure 7i, 7j). 


\section{JMSCR Vol||05||Issue||10||Page 29567-29585||October}

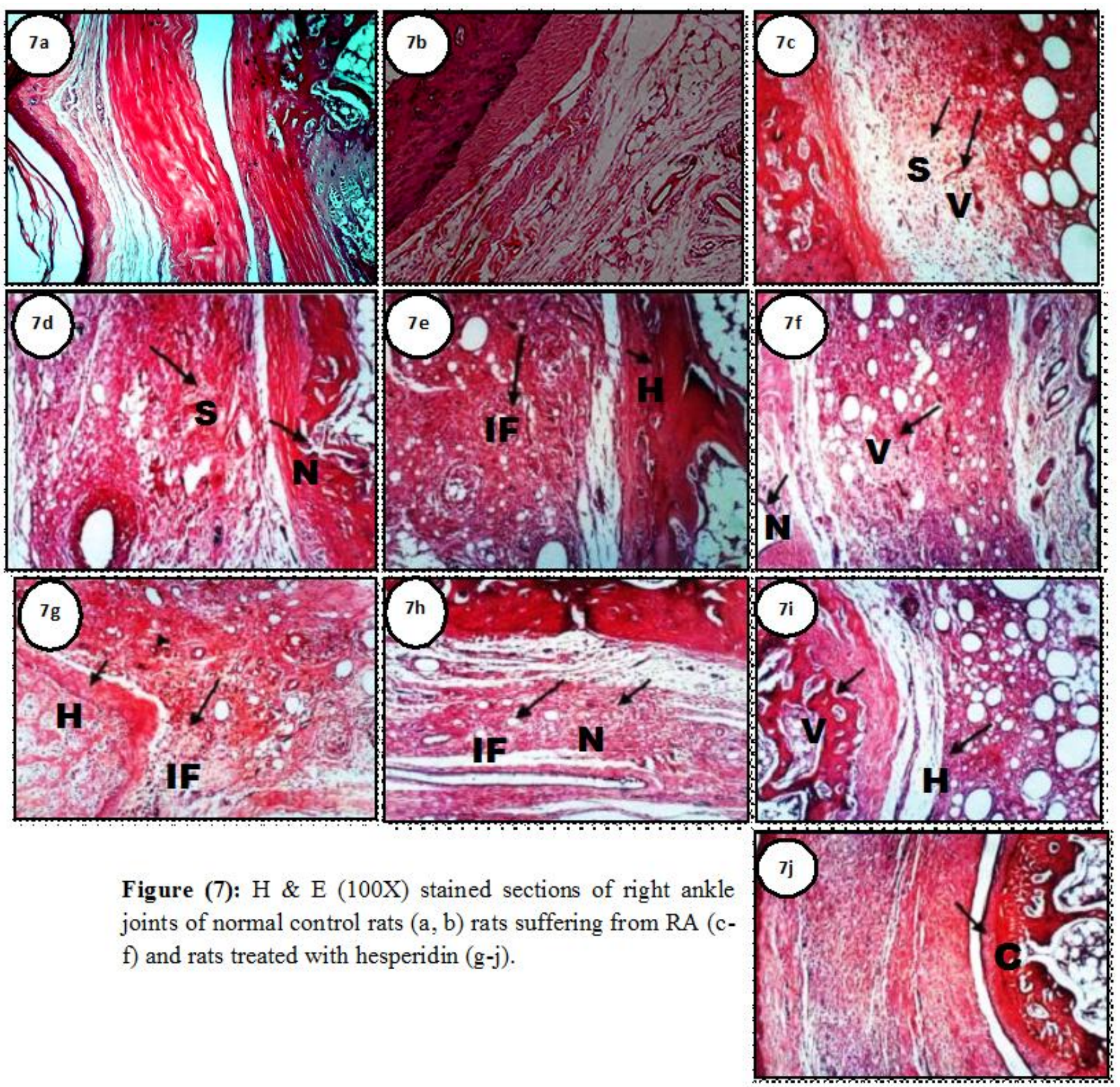

Slides are showing normal histological structure of the articular cartilage of subgroup IA (7a) and subgroup IIA (7b). Slides are also showing S: infiltration with stellate cells, IF: inflammatory cells infiltration, V: high vascularization and $\mathbf{N}$ : necrosis of articular cartilage in subgroup IB (7c, 7d) and subgroup IIB (7e, 7f). However, the pathological changes are more extensive with massive inflammatory cells infiltration in subgroup IIB. Slides are showing IF: inflammatory cells infiltration, $\mathbf{H}$ : hyperplasia of synovial cells, and V: high vascularization in subgroup IC (7g, 7h) and subgroup IIC (7i, 7j). However, there is $\mathbf{C}$ : new cartilage formation with moderate inflammatory cells infiltration in subgroup IIC.

\section{Discussion}

RA is a disabling disease that needs rapid appropriate treatment at the onset of the disease to prevent permanent deformities that would affect a patient's occupation, income and quality of life ${ }^{(17)}$.
Treating RA by NSAIDs, DMARDs and glucocorticoids may cause severe adverse reactions and do not significantly improve the long-term disease outcome ${ }^{(4)}$. Due to these facts, the exploration of new anti-RA drugs with high 
efficacy and less toxicity are eagerly needed. Adjuvant arthritis models by as SC. injection of CFA to rats lead to development of RA and is predictive of the clinical efficacy of many drugs in human $\mathrm{RA}^{(18)}$. AIA can be compounded by systemic disease, infiltration of inflammatory cells, and hyperplasia of synovial membrane in association with destruction of joints looking like RA in humans ${ }^{(19)}$.

The present study was designed to evaluate the efficacy of the use of hesperidin for one and two weeks on ankle diameter, serum levels of RF, serum levels of pro-inflammatory biomarkers (IL$1 \beta$ and TNF- $\alpha$ ), serum anti-inflammatory cytokines (IL-4 and IL-10), oxidative stress in liver homogenate (GSH, MDA, NO and SOD) and histopathology of ankle joint on progression and severity of joint damage of adjuvant-induced rheumatoid arthritis in male rats. The present data revealed that use of hesperidin caused a significant amelioration of serum proinflammatory cytokines, liver oxidative stress and joint damage of adjuvant-induced rheumatoid arthritis in male rats.

Molecular pathogenesis of RA remains unclear, but hyperplasia of the synovial membrane can be explained by both hyperproliferation of synovial fibroblasts, and massive infiltration of inflammatory immune cells including T-cells and innate immune cells ${ }^{(20)}$. The extensive increase in the number of inflammatory $\mathrm{T}$ cells and macrophages into the joints occurs through a complex series of adhesion and migratory events and leads to joint destruction, erosive and systemic bone loss ${ }^{(3)}$. The possible mechanism of RA caused by CFA SC. Injection may be due to increase in the activity of antigen presenting cells (APC), leading to the presentation to auto reactive T cells ${ }^{(21)}$.

In the present study, the increased ankle joint circumference of right hind leg of arthritic rats and serum RF significantly decreased as a result of treatment with hesperidin. This may be attributed to the reduction in edema, attenuation of inflammatory process and the reduction of synovial tissue hyperplasia as indicated by the histological results of joint in the present study. These results run parallel to several reports showed that treatment of rats with hesperidin significantly attenuated secondary paw swelling and reduced the polyarthritis index of AIA rats and its mechanism is related, at least in part, to its immunomodulatory properties ${ }^{(22,23)}$. It is possible that hesperidin may decrease ankle edema by inhibiting phospholipase A2, lipoxygenase, and cyclooxygenase (COX) enzymes. It has been noted that hesperidin affected the immune system through up-regulation the function of dysfunctional $\mathrm{T}$ lymphocytes and down-regulation of the over-activated macrophages (24).

In RA, inflammatory process involves many different types of cells and a complex cytokine network that determines the degree and extent of inflammation $^{(25)}$., IL-1 and TNF $\alpha$ are proinflammatory cytokines that stimulate synovial fibroblasts and adjacent chondrocytes thereby secreting enzymes that degrade proteoglycans, collagen, and connective tissues, resulting in tissue destruction. TNF- $\alpha$ being a key inflammatory mediator triggers an increase in synovial proliferation, production of other secondary mediators and also induces osteoclast differentiation which leads to joint destruction ${ }^{(26)}$. Increased serum level of IL- $1 \beta$ induced COX expression, knee joint inflammation and cartilage and bone resorption ${ }^{(27)}$.So, any drug therapy can suppress pro-inflammatory cytokines and NF- $\mathrm{BB}$ may be an appropriate therapeutic strategy for RA (28)

The current study revealed increased serum levels of both IL- $1 \beta$ and TNF- $\alpha$ in the rheumatoid arthritis groups. These results run parallel to several previous reports that showed RA progression accelerated by pro-inflammatory cytokines (TNF- $\alpha$ and IL-1 $\beta$ ) and chemokines ${ }^{(29,30)}$. In comparison to the arthritic control, the serum samples from the animals receiving hesperidin treatment demonstrated a significant drop in the levels of IL- $1 \beta$ and TNF- $\alpha$. These results run parallel to several reports showed that 
hesperidin treatment showed the least concentration of TNF- $\alpha$ and IL1 $\beta$ in rheumatoid arthritis rats ${ }^{(31,23)}$. However, hesperidin intake would not cause an inappropriate immune response in healthy people ${ }^{(24)}$. Hesperidin caused amelioration of joint destruction, synovial hyperplasia and infiltration of inflammatory cells, inhibited the production of IL- 1, IL- 6 , and TNF- $\alpha$ and restored the suppression of $\mathrm{T}$ - lymphocyte proliferation and production of IL-2 at the same time ${ }^{(32,7)}$.

IFN- $\beta, \quad$ IL-10 and IL-4, anti-inflammatory cytokines, has been shown to reduce cartilage destruction and inhibit angiogenesis ${ }^{(33)}$. The current study revealed decreased serum IL-4 and IL-10 in the rheumatoid arthritis control groups. In line with earlier studies, IL-4 and other suppressive cytokines that can be produced by Th2 cells (e.g. IL-10 and IL-13) suppress activity of several cell types that contribute to inflammation in the RA joints ${ }^{(34,35)}$. Treatment of the rheumatoid arthritis control male rats with hesperidin potentially increased the decreased serum IL-4 and IL-10. These results may be due to immunomodulatory effect of hesperidin as it affects the production of cytokines and enzymes that are involved in inflammation ${ }^{(36)}$.

Different inflammatory cell types as macrophages and neutrophils promote the formation of reactive oxygen species (ROS) which are involved in the progression of RA. There are higher levels of oxidative markers both in serum of RA patients (37) and also in liver of rats with experimental arthritis $^{(38)}$. Lipid peroxidation, protein oxidation, DNA damage and failure of antioxidant defense system lead to tissue damage and chronicity of the disease $^{(39)}$.

Our body fights against ROS by a non-enzymatic antioxidant defense system which includes vitamin $\mathrm{A}$ and $\mathrm{C}$, reduced glutathione (GSH), while enzymatic antioxidant includes superoxide dismutase (SOD), catalase, glutathione reductase (GR) and glautathione-S-transferase (GST). The most important antioxidant defense system in the body is GSH ${ }^{(39)}$. The current study revealed decreased liver homogenate GSH in the rheumatoid arthritis control groups. This result is in agreement with some other studies that noticed Low concentration of GSH found in the serum of RA patients ${ }^{(39,40)}$ and in the liver of arthritic rats (41). Treatment of the rheumatoid arthritis control male rats with hesperidin potentially increased the decreased liver homogenate GSH. These results may be due antioxidant effect of hesperidin.

In RA patients, Lipid peroxidation is considered a decisive mechanism of the chronicity of the disease. Several previous studies support the notion that lipid peroxidation-mediated inflammation promotes cell apoptosis through activation of $\mathrm{NF}-\kappa \mathrm{B}$ pathway in rheumatoid arthritis synovial cells ${ }^{(42)}$. In the present study, lipid peroxidation was measured in terms of MDA present in liver homogenate. The current study revealed increased levels of liver homogenate MDA in the rheumatoid arthritis control male rats. These results run parallel to several reports showing significantly higher serum MDA level in seropositive RA patients ${ }^{(43,44)}$ and in the liver and brain of rats with adjuvant arthritis ${ }^{(37)}$.

Treatment with hesperidin produced a significant decrease in lipid peroxidation biomarker ${ }^{(45)}$. Hesperidin has been reported to have a strong radical scavenging activity and affect the ERK/Nrf2 signaling pathway as well ${ }^{(46)}$. Hesperidin brought the liver and colon lipid peroxidation profiles back to normal levels. Hesperidin intake for rats having breast cancer reduced lipid peroxidation and reversing the marker enzymes to normal levels and reversed a doxorubicin-induced increase in MDA and a decrease in the GSH levels ${ }^{(36)}$.

The antioxidant enzymatic systems such as superoxide dismutases and catalase are involved in the protection of cells in case of extensive damage caused by excessive amounts of such highly reactive mediators. RA patients showed elevated serum MDA together with decreased activities of antioxidants including (CAT), superoxide dismutase (SOD), and glutathione peroxidase when compared to healthy individuals 
(47). The current study revealed decreased liver homogenate SOD in the rheumatoid arthritis control groups. This decreased SOD activity is in agreement with other studies as well ${ }^{(48,49)}$. One of the possible mechanisms of decreased SOD activity in RA might be due to the ROS mediated degradation of SOD during the detoxifying process ${ }^{(39)}$. Treatment of the rheumatoid arthritis control male rats with hesperidin potentially increased the decreased liver homogenate SOD. These results may be due antioxidant effect of hesperidin which results in normalization of the redox profile and reduce $\operatorname{ROS}^{(36)}$.

The peroxynitrite radical ONOO- generated by the reaction between $\mathrm{O} 2$ - and $(\mathrm{NO})$, can cause oxidative damage. Overproduction of NO contributes to $\mathrm{T}$ lymphocyte dysfunction and development of RA, and extra-articular manifestations in rheumatoid arthritis patients ${ }^{(50)}$. In synovitis, NO induces cytokine production, mitochondrial functions and chondrocyte apoptosis. In RA, there is increased intra-articular granulocytes inducible nitric oxide synthase (iNOS) which contributes to the intra-articular production of $\mathrm{NO}^{(51,52)}$.

In the present study, there was an increased level of liver homogenate $\mathrm{NO}$ in the rheumatoid arthritis rats. As reported in a previous study, the increased serum NO level of RA patients might be due to the hyperactivity of the NO forming enzyme, nitric oxide synthase ${ }^{(53)}$. Treatment of the rheumatoid arthritis control male rats with hesperidin potentially decreased liver homogenate NO level. This is in agreement with a previous work ${ }^{(45)}$. The possible mechanism is modulating the prostaglandin synthesis and COX-2 gene expression pathways and suppression of NF- $\kappa \mathrm{B}$ (54)

The synovium encapsulating RA joints shows remarkable changes with a marked increase in cellularity. RA shows hyper cellularity in joint cell lining and synovium lining expands from 1-2 cells deep to a depth of up to 10-20 cells. This is accompanied by synovial angiogenesis to support the proliferating synovium that may result in the perpetuation of inflammatory leukocyte migration. Histopathological changes in RA synovium occur even before patients develop pain in the affected joint ${ }^{(55)}$.

The images of hematoxylin and eosin staining sections of right ankle joints of each group were studied. No inflammation or tissue destruction was seen in sections from normal rats. In contrast, there was clear flooding of inflammatory cell infiltrate and severe loss of architecture in the joints of the rheumatoid arthritis male rats. In contrast, hesperidin treatment lowered the histopathological scores compared with the rheumatoid arthritis male rats and showed nearly normal joint architecture. This result was in agreement with a previous study that noticed that the arthritic group showed higher number of infiltrating cells, extensive bone degradation and synovial hyperplasia, which are hallmarks of RA (56). Treatment of adjuvant arthritis in rats with hesperidin was able to restore the histological changes to almost normal and attenuated vascular proliferation $^{(23,45)}$.

COI: None of the authors has commercial interests or associations which might pose conflicts.

Funding: No external funding sources are relevant to this submission.

\section{References}

1. Zhou Q, Zhou Y, Chen H, Wang Z, Tang $Z$ and Liu J. (2014). The efficacy and safety of certolizumabpegol (CZP) in the treatment of active rheumatoid arthritis (RA): a meta-analysis from nine randomized controlled trials. Int J ClinExp Med. 7:3870-3880.

2. Rudan I., Sidhu S., Papana A., S. J. Meng, Y. Xin-Wei, W. Wang, R. M. CampbellPage, A. R. Demaio, H. Nair, D. Sridhar, E. Theodoratou, B. Dowman, D. Adeloye, A. Majeed, J. Car, H. Campbell, W. Wang, K. Y. and Chan G. (2015). Global Health Epidemiology Reference, Prevalence of 
rheumatoid arthritis in low- and middleincome countries: A systematic review and analysis, Journal Global Health. 5, 010409.

3. Rosillo M. Angeles, Catalina Alarcón-dela-Lastra and Marina Sánchez-Hidalgo (2016). An update on dietary phenolic compounds in the prevention and management of rheumatoid arthritis. Food Funct., 7, 2943.

4. Raveendhara R, Bannuru MDFAGE, Elizaveta E, Vaysbrot MDMS, Matthew C, Sullivan BA, Thimothy E and McAlindon MDMPH. (2014). Relative efficacy of hyaluronic acid in comparison with NSAIDs for knee osteoarthritis: A systematic review and meta-analysis Semin. Arthritis. Rheu. 43:593-9.

5. Sinduhu G, Ratheesh M, Shyni GL, Nambisan B and Helen A. (2012). Antiinflammatory and antioxidative effects of mucilage of Trigonellafoenumgraecum (Fenugreek) on adjuvant induced arthritic rats. Int. Immunopharmacol. 12:205-11.

6. Zhan X., Yoichiro Ito, Jin-ru Liang, Jian-li Liu, Jiao He, and Wen-ji Sun (2014).Therapeutic effects of total steroid saponin extracts from the rhizome of DioscoreazingiberensisC.H.Wright in Freund's complete adjuvant induced arthritis in rats. IntImmunopharmacol. 23(2): 407-416.

7. Vabeiryureilai M., Lalrinzuali K. and Ganesh Chandra Jagetia (2015). Determination of Anti-Inflammatory and Analgesic Activities of a Citrus Bioflavanoid, Hesperidin in Mice. Immunochem Immunopathol.1:2.

8. Whitehouse MW (2007). Adjuvant arthritis 50 years on: The impact of the 1956 article by C. M. Pearson, 'Development of arthritis, periarthritis and periostitis in rats given adjuvants. Inflammation Research 56(4): 133-8.

9. Visnagri, A., Kandhare, A.D., Chakravarty, S., Ghosh, P., and Bodhankar, S.L.
(2014). Hesperidin, a flavanoglycone attenuates experimental diabetic neuropathy via modulation of cellular and biochemical marker to improve nerve functions. Pharmaceutical Biology, 52(7): 814-828.

10. Torre-Amione G., Kapadia S., C. Benedict, H. Oral, J.B. Young and Mann D.L (1996).Proinflammatory cytokine levels in patients with depressed left ventricular ejection fraction: a report from the Studies Of Left Ventricular Dysfunction (SOLVD). J Am CollCardiol, 27, pp. 1201-1206.

11. Mosmann T. (1996). Measurement of mouse and human interleukin-10. In: Current Protocols in Immunology. New York: Wiley, p. 6.14.3-6.14.8.

12. Jablonska E, Kiersnowska-Rogowska B and Ratajczak W. (2007). Reactive oxygen and nitrogen species in the course of BCLL. Adv Med Sci.52 1:154-158.

13. Ohkawa H, Ohishi N and Yagi K. (1979). Assay of lipid peroxidation in animal tissues by thiobarbituric acid reaction. Anal Biochem 95(2): 351-358.

14. Rahman, I., Mulier, B., Gilmour, P.S., Jeffery, P.K. \&MacNee, W. (2001). Oxidant induced lung epithelial cell tolerance: the role of intracellular glutathione and NF- $\mathrm{B}$. Biochem. Pharmacol. 62, 787-794.

15. Marklund, S., and Marklund, G. (1974). Involvement of the superoxide anion radical in the autoxidation of pyrogallol and a convenient assay for superoxide dismutase. European Journal of Biochemistry, 47(3): 469-474.

16. Chan YH (2003). Biostatistics102: Quantitative Data - Parametric \& Nonparametric Tests. Singapore Med J.; 44(8): 391-396.

17. Vanichapuntu M., PuchaniyadaPhuekfon, Parawee Suwannalai, Oravan Verasertniyom, Kanokrat Nantiruj and Suchela 
Janwityanujit (2010). Are anti-citrulline autoantibodies better serum markers for rheumatoid arthritis than rheumatoid factor in Thai population? Rheumatol Int. 30:755-759.

18. Hegen M, Keith Jr JC, Collins $M$ and Nickerson-Nutter CL. (2008): Utility of animal models for identification of potential therapeutics for rheumatoid arthritis. Ann Rheum Dis.67:1505-15.

19. Gandomani MZ and Malati EF (2014). Evaluation of Protective Efficacy of Avicennia marina (Forssk.) Vierh Leaves against Complete Freund's Adjuvantinduced Arthritis in Wistar. Iranian J. Pharm. Res. (IJPR) 13(3): 945-951.

20. Komatsu N. and Takayanagi H. (2012). Inflammation and bone destruction in arthritis: synergistic activity of immune and mesenchymal cells in joints, Front. Immunol., 3, 77.

21. Gomes R. Pinheiro, ElisangelaBressan, Tatiane Morgana da Silva, Monique da Silva Gevaerd, Carlos RogérioTonussi and Susana Cristina Domenech (2013). Standardization of an experimental model suitable for studies on the effect of exercise on arthritis. einstein. 11 (1):76-82.

22. Rong L., Jun Li, Li Cai, Cheng-mu Hu and Lei Zhang (2008). Suppression of adjuvant arthritis by hesperidin in rats and its mechanisms. Journal of Pharmacy and Pharmacology. 60: 221-228.

23. Bhalekar MR, Madgulkar AR, Aswar M, Mariam G and Desale P. (2016). A Comparative Study of Oral and Topical Administration of Hesperidin Lipid Nanoparticles in Rheumatoid Arthritis. Austin Arthritis. 1(2): 1010.

24. Parhiz H., Ali Roohbakhsh, Fatemeh Soltani, RaminRezaee and Mehrdad Iranshahi (2015). Antioxidant and AntiInflammatory Properties of the Citrus Flavonoids Hesperidin and Hesperetin: An Updated Review of their Molecular
Mechanisms and Experimental Models. Phytotherapy Research Phytother. Res. 29: 323-331.

25. Sivalingam S. P., Julian T., Sheila Vasoo, SzuTienThio, Connie Tse and Kok-Yong Fong (2007). In vivo Pro- and Antiinflammatory Cytokines in Normal and Patients with Rheumatoid Arthritis. Ann Acad Med Singapore. 36:96-9.

26. Fishman P and Yehuda SB. (2010). Rheumatoid Arthritis: History, Molecular Mechanisms and Therapeutic Applications. A3 Adenosine Receptors from Cell Biology to Pharmacology and Therapeutics. Springer Science Business Media B.V. P.A. Borea (ed). 291-299.

27. Wang B. (2014).Anti-arthritic effect of astragaloside IV and its molecular mechanism. Inflamm Cell Signal. 1: e130.

28. Jeoung B., Kyung Dong Lee, Chang-Su $\mathrm{Na}$, Young-Eok Kim, BoA Kim and Young Ran Kim (2013). Ganghwaljetongyeum, an anti-arthritic remedy, attenuates synoviocyte proliferation and reduces the production of proinflammatory mediators in macrophages: the therapeutic effect of GHJTY on rheumatoid arthritis. BMC Complementary and Alternative Medicine.13:47.

29. Nakamura T, Fujihara S, YamamotoNagata K, Katsura T, Inubushi T, Tanaka E (2011). Low-intensity pulsed ultrasound reduces the inflammatory activity of synovitis. Ann Biomed Eng. 39(12):29642971.

30. Uzair A. S. Shah, Huma Jawed, Shahid I. Awan, ShaziaAnjum, and Shabana U. Simjee (2013). The Anti-Arthritic and Immune-Modulatory Effects of NHAG: A Novel Glucosamine Analogue in Adjuvant-Induced Arthritis. BioMed Research International. Article ID 487610, 13 pages.

31. Bentli R, Ciftci O, Cetin A, Unlu M, Basak N and Cay M (2013). Oral 
administration of hesperidin, a citrus flavonone, in rats counteracts the oxidative stress, the inflammatory cytokine production, and the hepatotoxicity induced by the ingestion of $2,3,7,8$ tetrachlorodibenzo-p-dioxin (TCDD). Eur. Cytokine Netw 24: 91-96.

32. Li R., Li, J., Cai, L., Hu, C. and Zhang, L. (2008). Suppression of adjuvant arthritis by hesperidin in rats and its mechanisms. Journal of Pharmacy and Pharmacology, 60(2): 221-228.

33. Heo YJ, Joo YB, and Oh HJ (2010). IL-10 suppresses Th17 cells and promotes regulatory $\mathrm{T}$ cells in the $\mathrm{CD} 4+\mathrm{T}$ cell population of rheumatoid arthritis patients. ImmunolLett. 127:150-6.

34. Van Roon, Joël AG, Catharina AFM Glaudemans, Johannes WJ Bijlsma and Floris PJG Lafeber (2003). Differentiation of naive CD4+ $\mathrm{T}$ cells towards $\mathrm{T}$ helper 2 cells is not impaired in rheumatoid arthritis patients. Arthritis Research \& Therapy Vol 5 No 5.

35. Shen H., Liping Xia and Jing Lu (2013). Interleukin-4 in rheumatoid arthritis patients with interstitial lung disease: a pilot study. Indian J Med Res 138, pp 919921.

36. Roohbakhsh A., HamidehParhiz, Fatemeh Soltani, RaminRezaee and Mehrdad Iranshahi (2015). Molecular mechanisms behind the biological effects of hesperidin and hesperetin for the prevention of cancer and cardiovascular diseases. Life Sciences 124. 64-74.

37. Wendt MMN, Sá-Nakanishi AB, Ghizoni CVC, Bersani-Amado CA, Peralta RM and Bracht A. (2015). Determination of oxidative stress in the brain of rats with adjuvant-induced arthritis. ExpMolPathol. 98:549-557.

38. Bracht A, Silveira SS, Castro-Ghizoni CV, Sá-Nakanishi AB, Oliveira MRN and Amado CA (2016). Oxidative changes in the blood and serum albumin differentiate rats with monoarthritis and polyarthritis. Springer Plus. 5:36.

39. Mateen S., ShaguftaMoin, Abdul Qayyum Khan, AtifZafar and Naureen Fatima (2016):. Increased Reactive Oxygen Species Formation and Oxidative Stress in Rheumatoid Arthritis. PLoS ONE 11(4): e0152925.

40. kumar D. Vijaya, Suresh K and Manoharan S. (2006). Lipid peroxidation and antioxidant status in blood of rheumatoid arthritis patients. Indian $\mathbf{J}$ ClinBiochem. 21: 104-108.

41. Comar JF, Sá-Nakanishi AB, Oliveira AL, Wendt MMN, Bersani-Amado CA and Ishii-Iwamoto EL. (2013). Oxidative state of the liver of rats with adjuvant-induced arthritis. Free RadicBiol Med. 58:144153.

42. Yin G., Ying Wang, Xiao-min Cen,Min Yang, Yan Liang, and Qi-bingXie (2015). Lipid Peroxidation-Mediated Inflammation Promotes Cell Apoptosis through Activation of NF- $\kappa \mathrm{B}$ Pathway in Rheumatoid Arthritis Synovial Cells.Hindawi Publishing Corporation Mediators of Inflammation. Article ID 460310, 10 pages.

43. Hassan MQ, Hadi RA, Al-Rawi ZS, Padron VA and Stohs SJ. (2001).The glutathione defense system in the pathogenesis of rheumatoid arthritis. J ApplToxicol. 21:69-73.

44. Ali AM, Habeeb RA, El-Azizi NO, Khattab DA, Abo-Shady RA and Elkabarity RH. (2014). Higher nitric oxide levels are associated with disease activity in Egyptian rheumatoid arthritis patients. Rev. Bras. Reumatol. 54.

45. Umar S., Anubhav Kumar, Mir Sajad, JamilZargan, Md. Meraj Ansari, Sayeed Ahmad, Chandra Kant Katiyar, Haider A. Khan (2013). Hesperidin inhibits collageninduced arthritis possibly through 
suppression of free radical load and reduction in neutrophil activation and infiltration. Rheumatol Int.33:657-663.

46. Elavarasan J., Velusamy P., T. Ganesan, S.K. Ramakrishnan, D. Rajasekaran and K. Periandavan (2012). Hesperidin-mediated expression of $\mathrm{Nrf} 2$ and upregulation of antioxidant status in senescent rat heart, J. Pharm. Pharmacol. 64. 1472-1482.

47. Hadi V, Kheirouri S, Alizadeh M, Khabbazi AR and Hosseini H. (2016). Effects of Nigella sativa oil extract on inflammatory cytokine response and oxidative stress status in patients with rheumatoid arthritis; a randomized, double-blind, placebo-controlled clinical trial. Avicenna J Phytomed, 6 (1): 34-43.

48. Mohamad A, Khaleka MAA, Elsalawya AM and Hazaab SM. (2011). Assessment of lipid peroxidation and antioxidant status in rheumatoid arthritis and osteoarthritis patients The Egyptian Rheumatologist. 33: 179-185.

49. Kripa KG, Chamundeeswari D, Thanka J and Uma Maheswara Reddy C. (2011). Modulation of inflammatory markers by the ethanolic extract of Leucasaspera in adjuvant arthritis. J Ethnopharmacol. 134:1024-7.

50. Brenol CV, Chies JA, Brenol JC, Monticielo OA, Franciscatto P, Birriel F, Neves AG and Xavier RM. (2009). Endothelial nitric oxide synthase T-786C polymorphism in rheumatoid arthritis: association with extraarticular manifestations. Clin Rheumatol., 28: 201-205.

51. Marwan S.M. AL-NIMER, Samir AbdulHassan AL-OBAIDI, Khalid S. and ALDULAIMI (2010). Serum nitric oxide and peroxynitrite levels in adult sero-positive rheumatoid arthritis treated with disease modifying antirheumatic drugs: a preliminary report. Turk J Med Sci; 40 (2): 191-197.
52. Jikimoto T, Nishikubo $\mathrm{Y}$ and Koshiba $\mathrm{M}$ (2002).Thioredoxin as a biomarker for oxidative stress in patients with rheumatoid arthritis. MolImmunol; 38:765-72.

53. Mäki-Petäjä MK, Cheriyan J, Booth $\mathrm{AD}$, Hall FC, Brown $\mathrm{J}$ and Wallace SML (2008). Inducible nitric oxide synthase activity is increased in patients with rheumatoid arthritis and contributes to endothelial dysfunction. Inter. J. Card. 129: 399-405.

54. Woo CC, Kumar AP, Sethi G and Tan KH. (2012).Thymoquinone: potential cure for inflammatory disorders and cancer. BiochemPharmacol, 83: 443-451.

55. Bartok Beatrix and Firestein Gary S. (2010). Fibroblast-like synoviocytes: key effector cells in rheumatoid arthritis. Immunol Rev. 233(1): 233-255.

56. Wei XU, MINGQING HUANG, YUQIN ZHANG, HUANG LI, HAIYIN ZHENG, LISHUANG YU, KEDAN CHU, YU LINand LIDIAN CHEN (2016). Extracts of Bauhinia championii (Benth.) Benth. attenuate the inflammatory response in a rat model of collagen-induced arthritis. MOLECULAR MEDICINE REPORTS 13: 4167-4174. 